\title{
Total antioxidant potential of juices, beverages and hot drinks consumed in Egypt screened by DPPH in vitro assay
}

\author{
By Mohamed Fawzy Ramadan-Hassanien
}

\author{
Biochemistry Department, Faculty of Agriculture, Zagazig University, Zagazig 44511, \\ Egypt (e-mail: mframadan@zu.edu.eg)
}

\section{RESUMEN}

Potencial antioxidante total de zumos, bebidas y bebidas calientes consumidas en Egipto determinadas mediante ensayo in vitro con DPPH.

Las plantas comestibles contienen diferentes clases y tipos de antioxidantes y el conocimiento de su potencial antioxidante total (TAP), que es la capacidad acumulativa de los componentes de los alimentos para captar radicales libres, debería ser útil en estudios epidemiológicos. De acuerdo a esto, una variedad de zumos de fruta, bebidas calientes y bebidas consumidas habitualmente en Egipto fueron analizadas usando un ensayo in vitro con DPPH. El orden de efectividad de los zumos de frutas en inhibir los radicales libres fue el siguiente: zumo de uva tinta $>$ zumo de mango $>$ zumo de guayaba $>$ zumo de macedonia de frutas $>$ zumo de piña >zumo de naranja > zumo de cereza $>$ zumo de manzana. Entre las bebidas y bebidas calientes, el té seguido por el café son los que tuvieron mayores TAPs. Estos datos confirman que el zumo de uva, el té y el café son buenas fuentes de antioxidantes.

PALABRAS CLAVE: Bebidas - Bebidas calientes - Café - Ensayos con DPPH - Potencial antioxidante - Té Zumos.

\section{SUMMARY}

Total antioxidant potential of juices, beverages and hot drinks consumed in Egypt screened by DPPH in vitro assay.

Plant foods contain different classes and types of antioxidants and knowledge of their total antioxidant potentia (TAP), which is the cumulative capacity of food components to scavenge free radicals, would be useful for epidemiological purposes. To accomplish this, a variety of fruit juices, hot drinks and beverages commonly consumed in Egypt were analyzed using in vitro DPPH assay. The order of effectiveness of fruit juices in inhibiting free radicals was as follows: red grapes juice $>$ mango juice $>$ guava juice $>$ cocktail juice $>$ pineapple juice $>$ orange juice $>$ cherry juice $>$ apple juice. Among beverages and hot drinks, teas followed by coffees had the greatest TAP. These data confirm grape juice, teas and coffees as good dietary sources of antioxidants.

KEY-WORDS: Antioxidant potential - Juices - Beverages - Hot drinks - Tea - Coffee - DPPH assay.

\section{INTRODUCTION}

Fruit juice, beverages and hot drinks have received particular attention, because they contain high amounts of known antioxidants such as polyphenols, vitamin $\mathrm{C}$, vitamin E, Maillard reaction products, $\beta$-carotene, and lycopene. The consumption of fruit juices, beverages and hot drinks has been inversely associated with morbidity and mortality from degenerative diseases (Gillman et al., 1995; Rimm et al., 1996; Cohen et al., 2000; La Vecchia et al., 2001; Terry et al., 2001; Rodríguez-Bernaldo de Quirós and Costa, 2006). It is not known which dietary constituents are responsible for this association, but antioxidants appear to play a major role in the protective effect of plant foods (Gey, 1990; Gey et al., 1991; Willett, 1991; Liyana-Pathirana et al., 2006; RodríguezBernaldo de Quirós and Costa, 2006). Epidemiologic studies that analyze the health implications of dietary components rely on the intake estimates in sample populations found in databases that list the component's content in commonly consumed foods. Therefore, the availability of appropriate and complete food composition data is crucial. Due to the chemical diversity of antioxidant compounds present in foods, complete databases on food antioxidant contents are not yet available. In addition, levels of single antioxidants in food do not necessarily reflect their total antioxidant potential (TAP); this also depends on the synergic and redox interaction among the different molecules present in the food (Ramadan et al., 2003; Ramadan and Moersel, 2007). Finally, geographical differences in food composition data should be considered when applying compositional databases to regional surveys.

The relevance of TAP as a new tool for investigating the relationship between dietary antioxidants and oxidative stress-induced pathologies seems confirmed by the data from a recent population-based case control study, which showed an inverse correlation between the diet TAP and the risk of both cardiac and distal gastric cancer (Serafini et al., 2002). These relationships emerged in spite of the use of a very incomplete database of total antioxidant potential, highlighting the potentiality of the TAP as a descriptor of the diet. Several methods were developed recently for measuring the total antioxidant capacity of food and beverages (Wang et al., 1997; Benzie and Strain, 1999; Brenzie and Szeto, 1999; Pellegrini et al., 2000; Ramadan et al., 2003; Ramadan and 
Moersel, 2006, 2007); these assays differ in their chemistry (generation of different radical and/or target molecules) and in the way end points are measured.

According to the Industrial Modernization center (IMC) 2007 report (www.aegypten.ahk.de), Egypt can become the regional leader in the export of fruit juices. The report estimates Egypt's potential for market expansion of fruit juice to be as much as 730 million US\$ by 2020. Overall exports of fruit juice have grown from 713,000 US $\$$ in 1998 , to 15 million US\$ in 2006, with the US market now absorbing more than $65 \%$ of Egyptian fruit exports. On the other hand, Egypt is the largest market for tea and coffee in the Middle East, not only because of its 70 million citizens, but also due to the penetration of black tea and coffee as the main drink both indoors and outdoors (www.euromonitor.com/Hot_Drinks_in_Egypt). The objective of this work was to examine if the TAP assay in its recently published improved version (Ramadan and Moersel, 2006, 2007) is suitable for characterizing the antioxidant properties of commonly marketed Egyptian fruit juices, hot drinks and beverages to obtain robust data useful for determining the potential intake of antioxidants in Egyptian population studies as well as contributing to a better understanding of the role of different antioxidant juice ingredients.

\section{EXPERIMENTAL}

\subsection{Chemicals}

1,1-diphenyl-2-picrylhydrazyl (DPPH, approximately $90 \%$ ) was from Sigma (St. Louis, Mo, USA). Methanol of HPLC grade was used throughout the experiments.

\subsection{Fruit juices and beverages}

Three samples for each item were purchased from different markets in Zagazig (Egypt). Samples were then prepared and analyzed for TAP, as reported below. Like other nutrients, the estimation of the overall dietary intake of TAP does not require an estimate of the variance for any single food item if the value of the given food as consumed by the responder is sufficiently close to the average value. The same approach was used previously to generate food TAP data (Proteggente et al., 2002). The following fruit juices were purchased in local supermarkets: orange, cherry, apple, pineapple, guava, mango, and fruit cocktail (mixed fruits). Beverages (Anise, Hibiscus, Titia, Cinnamon, Chamomile, Caraway and Peppermint) and teas (black, green and with lemon) were prepared by infusion $(2 \mathrm{~g})$ in $200 \mathrm{~mL}$ boiling water for $5 \mathrm{~min}$. Soluble coffee, Turkish coffee and Cappuccino were prepared by solubilizing the samples $(2 \mathrm{~g})$ in $200 \mathrm{~mL}$ of boiling water for $5 \mathrm{~min}$. To avoid the presence of insoluble components, soluble coffee,
Turkish coffee and Cappuccino (cold to room temperature) were adequately and equally diluted in high purity water $(1: 10 \mathrm{v} / \mathrm{v})$. Diluted samples were centrifuged for $5 \mathrm{~min}$ at $1000 \times \mathrm{g}$, and the supernatant was collected and analyzed without further preparation.

\subsection{Radical scavenging activity toward DPPH radical}

Radical scavenging activity and the presence of hydrogen donors in juice and beverage samples were examined by reduction of DPPH in methanol according to Ramadan et al. (2003). A methanolic solution of DPPH radicals was freshly prepared at a concentration of $10^{-4} \mathrm{M}$. The radical, in the absence of antioxidant compounds, was stable for more than $3 \mathrm{~h}$ of normal kinetic assay. For evaluation, $100 \mu \mathrm{L}$ of each sample was mixed with $500 \mu \mathrm{L}$ Methanolic solution of DPPH radicals $\left(10^{-4} \mathrm{M}\right)$ and the mixture was vortexed for $10 \mathrm{~s}$ at ambient temperature. Against a blank of methanol without DPPH, the decrease in absorption at $515 \mathrm{~nm}$ was measured in 1 -cm quartz cells after 30,60 and 120 min of mixing using a UV-260 visible recording spectrophotometer (Shimadzu, Kyoto, Japan). Antiradical action toward DPPH radical was estimated from the difference in absorbance with or without the sample (control) and the percent of inhibition was calculated from the following equation.

$\%$ Inhibition $=[($ absorbance of control absorbance of test sample)/ absorbance of control] $x 100$

The variation in the DPPH values for replicates was always between 3 to $10 \%$ relative standard deviation (RSD). When the RSD was higher than $10 \%$, the analyses were repeated to confirm the value. Three samples of each item were analyzed and the main values as well as the SD were given.

\section{Results and discussion}

The consumption of foodstuffs rich in antioxidants provides protection against cancer and cardio- and cerebro-vascular diseases. This protection can be explained by the capacity of these active compounds to scavenge free radicals, which are responsible for the oxidative damage of lipids, proteins and nucleic acids (Aruoma, 1998, Ramadan et al., 2003). The juices, hot drinks and beverages included in this study were chosen in such a manner that samples with high concentrations of different antioxidant groups are included; for example, berry juice known to be rich in anthocyanins, citrus juices containing flavanones and teas containing flavanols. Thus, the influences of these particular antioxidant groups on the overall antioxidant capacity can be considered. In this survey, the total antioxidant capacity of a variety of fruit juices, hot drinks and beverages found in the Egyptian market were evaluated using DPPH assay. At present, it is hard to find data in literature 
concerning the TAP of foods and drinks consumed in Egypt. Moreover, a comparison with other data in the literature will be problematic due to the large variability within the food item and the lack of standardization of the assay. For this discussion, the ranking order of the TAP values will be used. The described arrangement for the simple experiment uses the addition of stable radicals 1,1diphenyl-2-picrylhydrazyl (DPPH) to fruit juices and beverages which will be decomposed by components having antioxidant properties. By means of a spectrophotometric process, the disappearance of the DPPH radicals was recorded. Certain compounds react very rapidly with DPPH radicals, reducing the number of radical molecules corresponding to the number of available hydroxyl group. However, for the majority of the compounds tested, the mechanism is more complex. Free radical scavengers donate an electron to the free radical and this electron donation is associated with the disappearance of the DPPH radical absorbance. The lower the absorbance, the stronger the free radical scavenging activity is. Concerning the dose effect of the different juices and beverages, experiments were carried out using different doses as well as different DPPH reagent volumes. In general, a linear relationship was noted. When higher doses of juices and beverages were used stronger antiradical action was obtained, while when larger volumes of DPPH reagent were used lower antiradical performance was observed.

\subsection{Total antioxidant potential of fruit juices}

Using the same per volume basis the antiradical performance of fruit juices toward DPPH radicals was measured and compared. The order of effectiveness of fruit juices in inhibiting free radicals was as follow: red grape juice > mango juice > guava juice $>$ cocktail juice $>$ pineapple juice $>$ orange juice $>$ cherry juice. The antioxidative potential of the selected fruit juices, was further evaluated using galvinoxyl radicals also dissolved in methanol by means of electron spin resonance spectrometry and similar rankings in the activities were obtained (data not shown). Table 1 shows that during the test period, red grape juice had the highest TAP followed by mango juice. After $120 \mathrm{~min}$ incubation, 82.6 percent of DPPH radicals were quenched by red grape juice while mango juice was able to quench $63.7 \%$. Vitis vinifera fruits show a high concentration and a great variety of phenolic compounds. Thus, grape juice is a rich source of flavonoids and other phenolics in the human diet (Rice-Evans et al., 1996). It is also well known that red grapes and berries have high antioxidant capacity and this capacity is likely due to their high contents of phenolics and flavonoids such as anthocyanins (Macheix et al., 1990; Kahkonen et al., 1999; Kalt et al., 1999; Kakkinen et al., 1999; Halvorson et al., 2002; Pellegrini et al., 2000, Brenes et al., 2005, Davalos et al., 2005), which have been demonstrated to produce strong antioxidant activities in different model systems (Wang et al., 1997; Satue-Gracia et al., 1997). Positive health benefits of the consumption of grape juice, such as improvement in the endothelial function, increase in the serum antioxidant capacity, protection of LDL against oxidation, decrease in native plasma protein oxidation, and reduction in platelet aggregation, have also been reported (Davalos et al., 2005). On the other hand, mango, guava and pineapple fruit juices exhibited intermediate antioxidant capacity. This result is in agreement with the higher concentration of phenolic compounds, caroteinoids and vitamin $\mathrm{C}$ present in these juices (Yen and Lin, 1999; Shivashankara et al. 2004; Rodríguez-Bernaldo de Quirós and Costa, 2006). Among the fruit juices, cherry, followed by apple, had the lowest antioxidant capacity. In Egypt, the increase in consumption of ready-to-drink juices has been associated with a reduction in the consumption of fresh fruits. Mango, guava and orange juices, both fresh and packed, are the most consumed fruit juices by the Egyptian population. Differences in the antioxidant activities among fruit juices could be attributed to their differences in phenolic contents and compositions and to other non-phenolic antioxidants present in the samples.

\subsection{Total antioxidant potential of beverages, teas and coffees}

The tap of hot drinks and caffeine-rich beverages and the ranking order are presented in Table 2. Among the beverages analyzed, tea drinks were the most effective, with lemon-flavored tea followed by green tea then black tea having the greatest antioxidant capacity. After $2 \mathrm{~h}$ incubation, 93.5 percent of DPPH radicals were quenched by lemon-flavored tea while green tea was able to quench only $89.9 \%$. In teas, the antioxidant potential of green tea is considerably higher than that of black tea, according to the literature (Daglia et al., 2000; Richelle et al., 2001; Wei et al., 2006). This different behavior of teas is due to the changes occurring during the process of fermentation; the flavanols in green tea leaves (mainly catechins and their gallic esters) undergo an oxidative polymerization by polyphenol oxidase, which turns the leaves black. During oxidation, much of the catechin content in green tea is converted to oxyproducts, such as thearubingens and theaflavins, with a loss of antioxidant capacity (Richelle et al., 2001). In Egypt, per capita consumption of black tea in 2005 was around 1.26 $\mathrm{kg}$ (www.euromonitor.com/Hot_Drinks_in_Egypt).

Soluble coffee followed by Turkish coffee was also found to have high TAP. Turkish coffee, preferably flavored with cardamom, accounts for around $95 \%$ of fresh coffee value sales in Egypt (www.euromonitor.com/Hot_Drinks_in_Egypt). During coffee making, the roasting process leads to profound changes in the chemical composition and 
Table 1

Scavenging effect (percentage of remaining DPPH radical) of fruit juices during DPPH test as measured by changes in absorbance at $515 \mathrm{~nm}$

\begin{tabular}{lccc}
\hline & \multicolumn{3}{c}{ Incubation time } \\
\hline Red grape juice & $\mathbf{3 0} \mathrm{min}$ & $\mathbf{6 0} \mathrm{min}$ & $\mathbf{1 2 0} \mathrm{min}$ \\
Mango juice & $30.5 \pm 0.05$ & $21.7 \pm 0.03$ & $17.4 \pm 0.03$ \\
Guava juice & $41.3 \pm 0.06$ & $38.3 \pm 0.02$ & $36.3 \pm 0.04$ \\
Cocktail juice & $53.3 \pm 0.03$ & $47.1 \pm 0.02$ & $43 \pm 0.02$ \\
Pineapple juice & $67.5 \pm 0.05$ & $66.3 \pm 0.05$ & $66.1 \pm 0.03$ \\
Orange juice & $78.1 \pm 0.06$ & $74.3 \pm 0.05$ & $71.9 \pm 0.04$ \\
Moncherry juice & $81.5 \pm 0.06$ & $80.6 \pm 0.04$ & $79.4 \pm 0.04$ \\
Apple juice & $88.3 \pm 0.03$ & $85.9 \pm 0.04$ & $84.7 \pm 0.03$ \\
\hline Each value is the average of three determinations \pm SD & $89.7 \pm 0.06$ & $89.5 \pm 0.04$ \\
\hline
\end{tabular}

Each value is the average of three determinations $\pm S D$

Table 2

Scavenging effect (percentage of remaining DPPH radical) of beverages and hot drinks during DPPH test as measured by changes in absorbance at $515 \mathrm{~nm}$

\begin{tabular}{lccc}
\hline & \multicolumn{3}{c}{ Incubation time } \\
\hline Tea with lemon & $\mathbf{3}$ in & $\mathbf{6 0}$ min & $\mathbf{1 2 0} \mathrm{min}$ \\
Green tea & $10.4 \pm 0.01$ & $9.4 \pm 0.01$ & $6.5 \pm 0.01$ \\
Black tea & $10.3 \pm 0.01$ & $9.6 \pm 0.01$ & $9.5 \pm 0.01$ \\
Soluble coffee & $11.7 \pm 0.02$ & $10.6 \pm 0.01$ & $10.5 \pm 0.02$ \\
Titia & $14.0 \pm 0.03$ & $13.8 \pm 0.02$ & $13.6 \pm 0.02$ \\
Turkish coffee & $24.6 \pm 0.03$ & $23.0 \pm 0.03$ & $18.7 \pm 0.02$ \\
Peppermint & $33.2 \pm 0.02$ & $29.6 \pm 0.02$ & $23.5 \pm 0.03$ \\
Hibiscus & $42.6 \pm 0.03$ & $35.7 \pm 0.03$ & $29.4 \pm 0.02$ \\
Cappuccino & $63.9 \pm 0.04$ & $60.4 \pm 0.03$ & $57.1 \pm 0.03$ \\
Cinnamon & $66.1 \pm 0.05$ & $62.1 \pm 0.04$ & $61.5 \pm 0.03$ \\
Anise & $69.3 \pm 0.04$ & $69.1 \pm 0.03$ & $65.3 \pm 0.03$ \\
Caraway & $85.5 \pm 0.06$ & $83.4 \pm 0.04$ & $81.9 \pm 0.05$ \\
Chamomile & $87.3 \pm 0.05$ & $86.4 \pm 0.03$ & $84.7 \pm 0.04$ \\
\hline
\end{tabular}

Each value is the average of three determinations \pm SD

biological activities of the coffee bean, resulting in the generation of compounds derived from Maillard reaction, carbohydrates caramelization and pyrolysis of organic compounds (Daglia et al., 2000; López-Galilea et al., 2006). In roasted coffee most polyphenolic compounds are destroyed, but 
Maillard reaction compounds with antioxidant properties are generated, resulting in an increased antioxidant activity in the ,-carotene-linoleic acid model system (Daglia et al., 2000; SánchezGonzález et al., 2005).

It is well known that the antioxidative properties are correlated not only with the total amount of antioxidants, but also with the presence of selected compounds. It could be said that the TAP of fruit juice and beverages can be interpreted as the combined action of different endogenous antioxidants. The significantly stronger antiradical action of some fruit juices or beverages may be due to (i) the differences in content and composition of bioactives (ii) the diversity in structural characteristics of potential phenolic antioxidants present, (iii) a synergism of bioactives with other components present in each juice or beverages and (iv) the differences in kinetic behaviors of potential antioxidants. All these factors may contribute to the radical quenching efficiency of juices and beverages.

\section{CONCLUSION}

The validity of the TAP approach for investigating the role of antioxidants in the protective effect of food and drinks is growing. The data presented here confirm that the DPPH assay is a well-founded method and appropriate to survey the antioxidant capacities of juice and beverage samples. On the whole, the results are partially in good accordance with the literature data, partially not. Obviously, this is because of basically different survey parameters.Coupled with an appropriate questionnaire, this will allow the evaluation of the overall intake of antioxidant-equivalents in selected groups of the Egyptian population in relation to the incidence of oxidative stress-induced diseases.

\section{REFERENCES}

Aruoma OI. 1998. Free radicals, oxidative stress and antioxidants in human health and disease. Journal of American Oil Chemists Society 75, 199-212.

Benzie IFF, Strain JJ. 1999. Ferric reducing/antioxidant power assay: direct measure of total antioxidant activity of biological fluids and modified version for simultaneous measurement of total antioxidant power. Methods of Enzymology 299, 15-27.

Benzie IFF, Szeto YT. 1999. Total antioxidant capacity of teas by ferric reducing/antioxidant power assay. Journal of Agricultural and Food Chemistry 47, 633636.

Brenes CH, DelPozo-Insfran D, Talcott ST. 2005. Stability of copigmented anthocyanins and ascorbic acid in a grape juice model system. Journal of Agricultural and Food Chemistry 53, 49-56.

Cohen JH, Kristal AR, Stanford JL. 2000. Fruit and vegetable intakes and prostate cancer risk. Journal of the National Cancer Institute 92, 61-68.

Daglia M, Papetti A, Gregotti C, Berte F, Gazzani G. 2000. In vitro antioxidant and ex vivo protective activities of green and roasted coffee. Journal of Agricultural and Food Chemistry 48, 1449-1454.

Davalos A, Bartolome B, Gomez-Cordoves C. 2005. Antioxidant properties of commercial grape juices and vinegars. Food Chemistry 93, 325-330.

Gey KF, Puska P, Jordon P, Moser UK. 1991. Total antioxidant capacity of plant foods. Inverse correlation between plasma vitamin $\mathrm{E}$ and mortality from ischemic heart disease in cross-cultural epidemiology. American Journal of Clinical Nutrition 53, 326S-334S.

Gey KF. 1990. The antioxidant hypothesis of cardiovascular disease: epidemiology and mechanisms. Biochemical Society Transaction 18, 1041-1045.

Gillman MW, Cupples LA, Gagnon D, Posner BM, Ellison RC, Castelli WP, Wolf PA. 1995. Protective effect of fruits and vegetables on development of stroke in men. Journal of the American Medical Association 273, 1113-1117.

Halvorson BL, Holte K, Myhrstad MCW, Barikmo I, Hvattum E, Fagertun Remberg S, Wold AB, Haffner K, Baugerod H, Frost Andersen L, Moskaug JO, Hacobs DR, Blomhoff R. 2002. A systematic screening of total antioxidants in dietary plants. Journal of Nutrition 132 , 461-471.

Kahkonen MP, Hoia AI, Vuorela HJ, Rauha JP, Pihlaja K, Kujala TS, Heinonen M. 1999. Antioxidant activity of plant extracts containing phenolic compounds. Journal of Agricultural and Food Chemistry 47, 39543962.

Kakkinen S, Heinonen M, Karenlampi S, Mykkanen $\mathrm{H}$, Ruuskanen J, Torronen R. 1999. Screening of selected flavonoids and phenolic acids in 19 berries. Food Research International 32, 345-353.

Kalt W, Forney CF, Martin A, prior RL. 1999. Antioxidant capacity, vitamin $\mathrm{C}$, phenolics and anthocyanins after fresh storage of small fruits. Journal of Agricultural and Food Chemistry 47, 4638-4644.

La Vecchia C, Altieri A, Tavani A. 2001. Vegetables, fruit, antioxidants and cancer: a review of Italian studies. European Journal of Nutrition 40, 261-267.

Liyana-Pathirana CM, Shahidi F, Alasalvar C. 2006. Antioxidant activity of cherry laurel fruit (Laurocerasus officinalis Roem.) and its concentrated juice. Food Chemistry 99, 121-128.

López-Galilea I, Andueza S, di Leonardo I, Paz de Peña $\mathrm{M}$, Cid C. 2006. Influence of torrefacto roast on antioxidant and pro-oxidant activity of coffee. Food Chemistry 94, 75-80.

Macheix JJ, Fleuriet A, Billot J. 1990. Fruit phenolics. CRC Press, Boca Raton, FL.

Pellegrini N, Re R, Yang M, Rice-Evans CC. 1999. Screening of dietary carotenoids and carotenoid-rich fruit extracts or antioxidant activities applying the 2,2azobis(3-ethylenebenzothiazoline-6-sulfonic) acid radical cation decolorization assay. Methods of Enzymology 299, 379-389.

Pellegrini N, Simonetti P, Gardana C, Brenna O, Brighenti F, Pitta PG. 2000. Polyphenol content and total antioxidant activity of vini novelli (young red wines). Journal of Agricultural and Food Chemistry 48, 732-735.

Proteggente AR, Pannala AS, Paganga G, van Buren L, Wagner E, Wiseman S, van de Put F, Dacombe C, Rice-Evans CA. 2002. The antioxidant activity of regular consumed fruit and vegetables reflects their phenolic and vitamin C composition. Free Radical Research 36, 217-233.

Ramadan MF, Kroh LW, Moersel JT. 2003. Radical scavenging activity of black cumin (Nigella sativa L.), 
coriander (Coriandrum sativum L.) and niger (Guizotia abyssinica Cass.) crude seed oils and oil fractions. Journal of Agricultural and Food Chemistry 51, 6961-6969.

Ramadan MF, Moersel JT. 2006 Screening of the antiradical action of vegetable oils. Journal of Food Composition and Analysis 19, 838-842.

Ramadan MF, Moersel JT. 2007. Impact of enzymatic treatment on chemical composition, physicochemical properties and radical scavenging activity of goldenberry (Physalis peruviana L.) juice. Journal of the Science of Food and Agriculture 87, 452-460.

Rice-Evans CA, Miller NJ, Paganga G. 1996. Structureantioxidant activity relationship of flavonoids and phenolic acids. Free Radical Biology and Medicine 20, 933-956.

Richelle M, Travazzi I, Offord E. 2001. Comparison of the antioxidant activity of commonly consumed polyphenolic beverages (coffee, cocoa and tea) prepared per cup serving. Journal of Agricultural and Food Chemistry 49, 3438-3442.

Rimm EB, Aschiero A, Giovannucci E, Spiegelman D, Stampfer MJ, Willett WC. 1996. Vegetable, fruits and cereal fiber intake and risk of coronary heart disease among men. Journal of the American Medical Association 275, 447-451.

Rodríguez-Bernaldo de Quirós A, Costa HS. 2006. Analysis of carotenoids in vegetable and plasma samples: A review. Journal of Food Composition and Analysis 19, 97-111.

Sánchez-González I, Jiménez-Escrig A, Saura-Calixto F. 2005. In vitro antioxidant activity of coffees brewed using different procedures (Italian, espresso and filter). Food Chemistry 90, 133-139.
Satue-Gracia MT, Heinonen M, Frankel EN. 1997. Antioxidant activity of anthocyanins in LDL and lecithin liposome system. Journal of Agricultural and Food Chemistry 45, 3362-3367.

Serafini M, Bellocco R, Wolk A, Ekstrom AM. 2002. Total antioxidant potential of fruit and vegetables and risk of gastric cancer. Gastroenterology 123, 985-999.

Shivashankara KS, Isobe S, Al-Hag MI, Takenaka M, Shiina T. 2004. Fruit antioxidant activity, ascorbic acid, total phenol, quercetin, and carotene of Irwin mango fruits stored at low temperature after high electric field pretreatment. Journal of Agricultural and Food Chemistry 52, 1281-1286.

Terry P, Terry JB, Wolk A. 2001. Fruit and vegetable consumption in the prevention of cancer: an update. Journal of Internal Medicine 250, 280-290.

Wang H, Cao G, Prior RL. 1997. Oxygen radical absorbing capacity of anthocyanins. Journal of Agricultural and Food Chemistry 45, 304-309.

Wei Q-Y, Zhou B, Cai Y-J, Yang L, Liu ZL. 2006. Synergistic effect of green tea polyphenols with trolox on free radical-induced oxidative DNA damage. Food Chemistry 96, 90-95.

Willett WC. 1991. Micronutrients and cancer risk. Journal of the American Medical Association 53, 265S-269S.

Yen GC, Lin HT. 1999. Changes in volatile flavor components of guava juice with high-pressure treatment and heat processing and during storage. Journal of Agricultural and Food Chemistry 47, 20822087.

Recibido: 10/12/07 Aceptado: 12/2/08 